\title{
Flame Retardant Effects of Nano-Clinoptilolite on Acrylonitrile- Butadiene-Styrene (ABS) Nano-Composite
}

\author{
Aboulfazl Barati, Gholamreza Salbi, Taghi Miri \\ Department of Chemical Engineering, Faculty of Engineering, Arak University, Arak 38156-8-8349, Iran \\ Email: a-barati@araku.ac.ir,rskh_274@yahoo.com,t-miri@araku.ac.ir
}

\begin{abstract}
In recent years, intumescent technology has found a place in polymer science as a method of providing flame retardance to polymeric materials. On heating, fire-retardant intumescent material restricts the action of the heat flux or flame. The proposed mechanism is based on charred layer acting as physical barrier, which slows down heat and mass transfer between the gas and the condensed phases. In this paper, the flammability of intumescent fire-retardant acrylonitrile-butadiene-styrene (ABS) matrix composites consisting of hydromagnesite $(\mathrm{HMg})$ as an acid source and blowing agent, pentaerythritol (PER) as a carbonisation agent and natural zeolite (clinoptilolite rich, Kansar Shargh) as a synergistic agent were examined. The flammability of composites was characterized by limiting oxygen index (LOI) measurement and horizontal burning tests. A synergistic effect in flame retardancy was observed when natural zeolites were used in combination with HMg and PER
\end{abstract}

Keywords - Flame retardant; ABS; Nano-composite; Clinoptilolite; Intumescence.

\section{INTRODUCTION}

Acrylonitrile-butadiene-styrene (ABS) is a widely used thermoplastic material due to its good mechanical properties, chemical resistance and processing advantages [1]. In many applications, it is necessary to construct a flame-retarded composition for ABS resin [2].

The common flame retardants for ABS were halogencontaining compounds. Bromine-containing compounds such as decabromodiphenyl oxide (DBDPO), tetrabromobisphenol (TBBPA), 1,2-bis $(2,4,6-$ tribromophenoxy) ethane (BTBPOE), etc. have been regarded as very good flame retardants for ABS resin [3]. Although halogen-containing flame retardants show remarkable efficiency, they lead to environmental problems by generating great quantities of toxic and corrosive fumes during combustion which restricts the range of their application.

In recent years, intumescent technology has found a place in polymer science as a method of providing flame retardance to polymeric materials. On heating, fire-retardant intumescent material restricts the action of the heat flux or flame. The proposed mechanism is based on charred layer acting as physical barrier, which slows down heat and mass transfer between the gas and the condensed phases [4]. The flame retardant can cause a charred layer of carbon to form on the polymer surface. This can occur, for example, through the dehydrating action of the flame retardant generating double bonds in the polymer. These form the carbonaceous layer by cyclization and cross-linking. Combinations of flame retardants may produce a synergistic effect of great importance for practical use.

The alternative inorganic FRs is often incorporated at such high loadings, i.e. up to $50 \mathrm{wt} \%$, that there is a significant compromise in the final balance of properties for the composite, particularly toughness. Formation of a nanocomposite by addition of montmorillonite clay platelets (MMT) to the polymer is another potential approach which has been shown to be effective at low loadings ( $>5 \%$ ), and may lead to a better balance of physical properties. For example, nanocomposites of MMT with nylon 6 and with polypropylene (plus a PP grafted with maleic anhydride as a compatibilizer) have shown substantial improvement in the FR properties (up to $70 \%$ reduction in the peak heat release rate) with simultaneous improvements in modulus and strength. There is still some minimal compromise in composite toughness [5], and typically the state of disaggregation of the clay platelets, or exfoliation, is considered to be a key factor in developing good composite properties.

In this study, the goal was to increase the flame resistance of $\mathrm{ABS}$ and to investigate influence of natural zeolites on flame retardant additives. For this purpose, an intumescent flame retardant system was selected. Hydromagnesite $\left(4 \mathrm{MgCO}_{3} \cdot \mathrm{Mg}(\mathrm{OH})_{2} \cdot 4 \mathrm{H}_{2} \mathrm{O}\right)(\mathrm{HMg})$ was used as acid source and blowing agents and pentaerythritol (PER) was used as 
carbonisation compound in the intumescent system. Natural zeolite with nanometre size, clinoptilolite, was used for its synergism with intumescent flame retardant materials. For best flame retardant performance, optimum $\mathrm{HMg} / \mathrm{PER}$ ratio and zeolite loading were investigated. Flammability of samples was characterized with horizontal burning test (HB) and limiting oxygen index (LOI).

\section{EXPERIMENTAL}

\section{A. Materials}

Kansar Shargh zeolitic tuff having particle size below 75 $\mathrm{nm}$ and supplied by Kansaran Binaloud Company was used in this study (Fig 1). It was found, by XRD and XRF to contain $75 \mathrm{wt} \%$ of clinoptilolite. In addition to zeolitic phase, quartz, cristobalite, and $\mathrm{K}$-feldspar were detected in its X-ray diffraction diagram. It contained 50.69\% $\mathrm{SiO}_{2}, 8.03 \% \mathrm{Al}_{2} \mathrm{O}_{3}$, $1.97 \% \mathrm{Fe}_{2} \mathrm{O}_{3}, 1.21 \% \mathrm{~K}_{2} \mathrm{O}, 3.17 \% \mathrm{Na}_{2} \mathrm{O}, 9.34 \% \mathrm{CaO}, 0.91 \%$ $\mathrm{MgO}, 0.22 \% \mathrm{TiO}_{2}, 0.03 \% \mathrm{P}_{2} \mathrm{O}_{5}, 0.13 \% \mathrm{MnO}, 0.06 \% \mathrm{SO}_{2}$ and $24.24 \% \mathrm{H}_{2} \mathrm{O}$.

Hydromagnesite $(\mathrm{HMg})$ having soluble fraction in water below $1 \%$, and average particle size of $50 \mathrm{~nm}$ supplied by Nanotech Company, pentaerythritol (PER), having particle size below $75 \mathrm{~mm}$ supplied by Sigma Co., SAN and BR supplied by Tabriz and Arak Petrochemical Company and antioxidant, butylated hydroxy toluene, supplied by Sigma Co. were used in the experiments.

\section{B. Compounding}

ABS matrix composites were prepared by blending of SAN and BR, flame retardant materials ( $\mathrm{HMg}$ and PER), nano-sized clinoptilolite and antioxidant $(0.5 \%)$ by using a laboratory twin screw extruder (aspect ratio $=30$ ). Concentration of fillers was fixed at $20 \%$ mass of total amounts of composite. Amounts of $\mathrm{HMg}$ were changed in proportion to amounts of pentaerythritol $(2,1,0.5$, and 0.25 ratios). Clinoptilolite dried at $120^{\circ} \mathrm{C}$ was added with mass fractions of 1,2 and $5 \%$. Clinoptilolite and $\mathrm{HMg}$ were dried in an oven at $120{ }^{\circ} \mathrm{C}$ for over night. Samples were mixed at 60 revolutions per minute screw speed at $190{ }^{\circ} \mathrm{C}$. At first, SAN and BR was melted at $190{ }^{\circ} \mathrm{C}$ and then antioxidant $(0.5$ $\mathrm{wt} \%$ ) was added to the molten compound. Afterwards, clinoptilolite, $\mathrm{HMg}$ and PER were added. Mixed materials were hot pressed at $190{ }^{\circ} \mathrm{C}$ and 100 bar, into sheets having dimensions of $15 \times 15 \times 0.3 \mathrm{~cm}$. Composites were cut by bar shaped hollow die punch, with dimensions of $125 \times 12.5 \times 3$ $\mathrm{mm}$ for UL-94 test and $125 \times 6.5 \times 3 \mathrm{~mm}$ for LOI test.

\section{Flammability test}

Horizontal test method for rate of burning and extent and time of burning of self-supporting plastics in a horizontal position was constructed according to ASTM D 5020 and ASTM D 635 [6]

The limiting oxygen index (LOI) test method for measuring the minimum oxygen concentration to support candle-like combustion of composites was determined according to ASTM D 2863 [7].

\section{RESULTS AND DISCUSSION}

Horizontal burning test results, burning time, length and rate of composites in air are illustrated in Table 1.

While most of the composites did not burn in atmospheric conditions, some of them either completely or partially burned. This indicates that, some composites extinguished themselves in the atmosphere. Burning time and length must be taken into account when burning rates of all composites were compared with each other. None of the composites having high $\mathrm{HMg} / \mathrm{PER}$ (1 and 2) ratio burnt in air. Composites having low zeolite content $(1,2,5 \%)$ except the ones having low APP:PER (1:2 and 1:4) ratio also did not burn in horizontal burning tests. It was observed that the addition of zeolite to ABS matrix, decreased the flammability resistance of ABS, on the other hand addition of flame retardant materials increased the flammability resistance of ABS. However, their horizontal burning rates were lower than that of pure ABS. Burning rates of pure ABS, HMg:PER (1:2) and HMg:PER (1:4) + 1\% zeolite were $0.28,0.25$ and $0.21 \mathrm{~mm} / \mathrm{s}$, respectively. Composites having 10\% zeolite and HMg:PER ratio greater than 1 had generally higher burning rates (between 0.27 and $0.42 \mathrm{~mm} / \mathrm{s}$ ) than pure ABS (0.28). Samples with low HMg:PER ratio $(1: 4,1: 2)$ and $10 \%$ zeolite burning was complete but with a slower rate $(0.25-0.27 \mathrm{~mm} / \mathrm{s})$ than pure ABS. Results indicated that, flame retardant materials and low level zeolite addition enhanced flammability resistance of polymer. HB tests were not sufficient to show the synergism of flame retardants and zeolites thus limiting oxygen index of the samples were measured.

Fig. 2 shows the effects of flame retardant materials and zeolite on flammability of ABS separately. In order to research synergism, each material's effect on flammability of ABS should be known. The LOI value (19\%) was unchanged with addition of $20 \% \mathrm{HMg}$ into ABS. Carbonisation agent (PER) addition alone was not sufficient for providing char formation which was important for intumescent system since it decreased LOI value of ABS to $17 \%$.

Composites with zeolite also had lower LOI values than that of pure ABS. An increase in zeolite concentration in composite formulations leads to decrease in LOI up to $16 \%$. Fig. 3 illustrates the LOI values of flame retardant ABS composites versus HMg:PER ratios with different zeolite content. The LOI value of ABS rose from 19 to $32 \%$ with flame retardant $\mathrm{HMg}$ and PER addition at 1:1 ratio. Results indicated that the $\mathrm{HMg}$ had important role in intumescent flame retardant system. An increment in the HMg amount, increased LOI values of composites.

At low zeolite loading $(1,2,5 \mathrm{wt} \%)$, the LOI values of composites were higher than that of without zeolite formulation. Synergism between zeolite and flame retardant additives can be easily observed at low zeolite loading. Synergistic effect was observed in $\mathrm{HMg}$ :PER (2:1) and (1:1) ABS formulations having 2 and $5 \%$ zeolite loadings respectively. Two percent zeolite addition in HMg:PER $(1: 1)$ ABS composite increases the LOI values from 32 to $37 \%$. While the LOI of HMg:PER (1:1) ABS composite was 31\%, it was composite with $5 \mathrm{wt} \%$ of zeolite and HMg:PER $(2: 1)$ was $38 \%$ being the maximum LOI value among all flame retardant $\mathrm{ABS}$ composites. Zeolites act as a catalyst for the 
development of the intumescent carbonaceous material and stabilize the carbonaceous residue resulting from degradation of the intumescent shield.

TABLE 1. HORIZONTAL BURNING TEST RESULTS

\begin{tabular}{|l|l|l|l|}
\hline $\begin{array}{l}\text { Flame retardant } \\
\text { composite }\end{array}$ & $\begin{array}{l}\text { Burning } \\
\text { rate } \\
\text { (mm/s) }\end{array}$ & $\begin{array}{l}\text { Burning } \\
\text { length (mm) }\end{array}$ & $\begin{array}{l}\text { Burning } \\
\text { time (s) }\end{array}$ \\
\hline Pure ABS & 0.28 & 100.0 & 315 \\
\hline $\begin{array}{l}\text { HMg:PER } \\
(1: 4)+\text { +ABS }\end{array}$ & 0.26 & 45.4 & 135 \\
\hline $\begin{array}{l}\text { HMg:PER } \\
(1: 2)+\text { ABS }\end{array}$ & 0.23 & 25.3 & 163 \\
\hline $\begin{array}{l}\text { HMg:PER (1:4)+ } \\
1 \% \text { Zeolite+ ABS }\end{array}$ & 0.25 & 40.8 & 121 \\
\hline $\begin{array}{l}\text { HMg:PER (1:2)+ } \\
1 \% \text { Zeolite+ ABS }\end{array}$ & 0.21 & 100.0 & 412 \\
\hline $\begin{array}{l}\text { HMg:PER (1:2)+ } \\
2 \% \text { Zeolite+ ABS }\end{array}$ & 0.32 & 39.0 & 85 \\
\hline $\begin{array}{l}\text { HMg:PER (1:4)+ } \\
2 \% \text { Zeolite+ ABS }\end{array}$ & 0.22 & 100.0 & 408 \\
\hline $\begin{array}{l}\text { HMg:PER (1:2)+ } \\
5 \% \text { Zeolite+ ABS }\end{array}$ & 0.23 & 80.5 & 304 \\
\hline $\begin{array}{l}\text { HMg:PER (1:4)+ } \\
5 \% \text { Zeolite+ ABS }\end{array}$ & 0.25 & 100.0 & 321 \\
\hline $\begin{array}{l}\text { HMg:PER (1:1)+ } \\
5 \% \text { Zeolite+ ABS }\end{array}$ & 0.34 & 40.4 & 98 \\
\hline
\end{tabular}

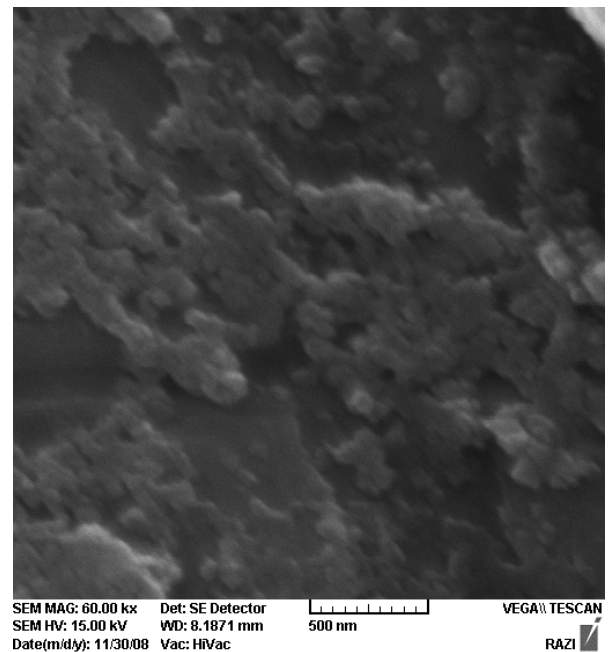

Fig. 1 SEM micrograph of cross-section of HMg+PER (1:4) $+5 \%$ Clinoptilolite + ABS.

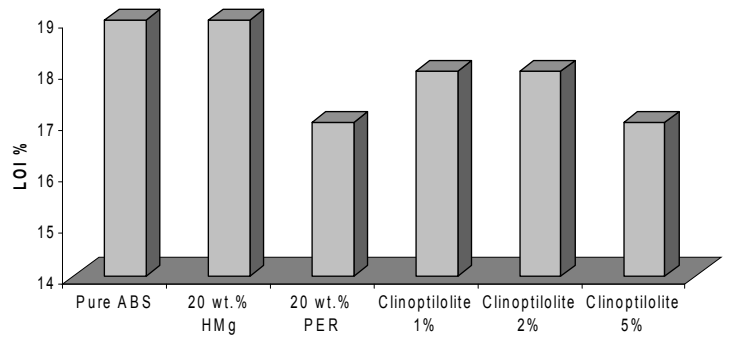

Fig. 2. Limiting oxygen index of ABS, 20 wt.\% $\mathrm{HMg}+\mathrm{ABS}, 20$ wt.\% PER + ABS and different clinoptilolite loading in ABS.

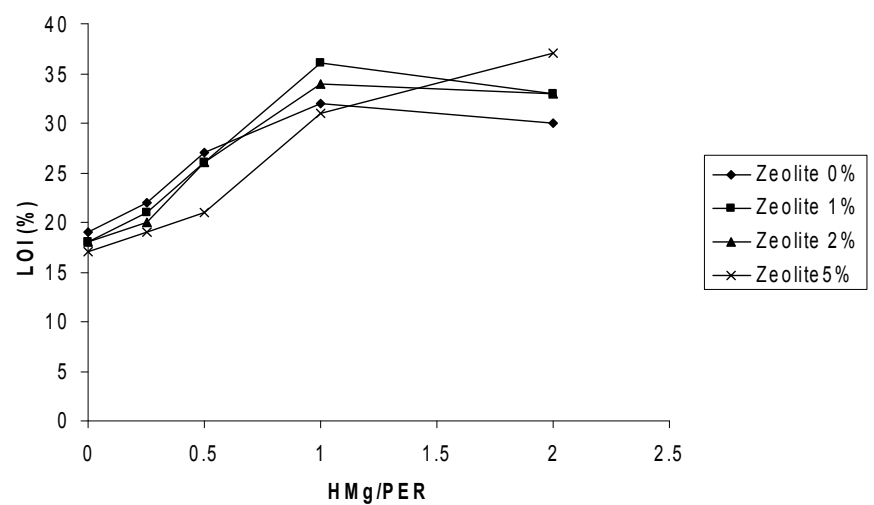

Fig. 3. Limiting oxygen index of all flame retardant ABS composites versus $\mathrm{HMg} / \mathrm{PER}$ ratio according to zeolite concentration.

\section{CONCLUSIONS}

A simple method of melt blending was used to prepare ABS/clinoptilolite nanocomposites incorporating the intumescent flame retardant, $\mathrm{HMg} / \mathrm{PER}$. A synergistic effect was found between $\mathrm{HMg} / \mathrm{PER}$ and clinoptilolite which improved thermal stability and flame retardancy.

\section{ACKNOWLEDGMENT}

The authors would like to thank Arak University for its financial support to this work.

\section{REFERENCES}

[1] D. W. Dong, S. Tasaka, S. Aikawa, S. Kamiya, N. Inagaki, Y. Inoue "Thermal degradation of acrylonitrile-butadiene-styrene terpolymer in bean oil", Polym. Degrad. Stab., vol. 73, pp.319-326, 2001.

[2] S. R. Owen, J. F. Harper, "Mechanical, microscopical and fire retardant studies of ABS polymers", Polym. Degrad. Stab., vol. 64, pp. 449-455, 1999.

[3] M. Brebu, T. Bhaskai, K. Murai, K. Muto, Y. Sakata, M. A. Uddin, "The individual and cumulative effect of brominated flame retardant and polyvinylchloride (PVC) on thermal degradation of acrylonitrilebutadiene-styrene (ABS) copolymer", Chemosphere, vol. 56, pp. 433-440, 2004.

[4] S. Bourbigot, M. Le Bras, R. Delobel, R. Decressain, J. P. Amourex, "Synergistic effect of zeolite in an intumescent process study of the carbonaceous structure using solid-state NMR", Faraday Transactions, vol. 92, pp. 149-158, 1996.

[5] M. Sain, S. H. Park, F. Suhara, S. Law, "Flame retardant and mechanical properties of natural fibre-PP composites containing magnesium hydroxide", Polym. Degrad. Stab., vol. 83, pp. 363-367, 2004.

[6] ASTM D 5025-91. Standard specification for a laboratory burner used for small-scale burning tests on plastic materials; 1991. [09.02].

[7] ASTM D 2863-91. Standard Test Method of measuring the minimum oxygen concentration to support candle-like combustion of plastics (oxygen index); 1991. [08.04]. 